\title{
Social Interaction of Local Communities With Migrants and Changes in The Structure of Local Communities (Study on Plural Society in Makassar Industrial Area)
}

\author{
$1^{\text {st }}$ Andi Agustang \\ Department of Sociology \\ Faculty of Social Science \\ Universitas Negeri Makassar \\ Makassar, Indonesia \\ andi.agustang@unm.ac.id
}

\author{
$2^{\text {nd }}$ Andi Tenri Pada \\ Department of Sociology \\ Universitas Khaerun Ternate \\ Ternate, Indonesia \\ anditenripada@gmail.com
}

\author{
$3^{\text {rd }}$ Bastiana \\ Departmen Public Administration \\ Faculty of Education \\ Universitas Negeri Makassar \\ Makassar, Indonesia \\ bastiana@unm.ac.id
}

\begin{abstract}
The complicity of social interaction (dynamic social relations) in an ethnic poly system is examined and analyzed using the "contingency linkage" model, which is the linkage of social interaction with the implementation of values and norms, social field network system, and the existence of creative individuals. The analysis model of the interrelationship between social interaction and structural transformation is a "stochastic" relationship with the main concept of structure and function. These two concepts are components of a functional perspective that are expanded with a network approach and the system plays a role.This research used descriptive analytic survey method, the type of research is explanation, supported by qualitative-quantitative approach that aims to test the hypothesis with correlation design and influence test. The analysis unit of the supervisor level is the leader of the sub-district, the village apparatus, the head of the RW, RT, the public figures as key information including other community figures who are entirely located and domiciled in the research location. The sampling used proportional random sampling (observation), interviews with questionnaires and free interviews. Data analysis is qualitative and quantitative. Result study showed that the implementation of values and norms, the nature of social networking systems, creative individuals were significantly influenced the social interaction. In particular the meaning of the implementation of values and norms refers more to the personality traits and moral values of local communities. The treatment of social networks is in line with the loose and the tight of local networks which contain traditionally and emotionally. Therefore, commitment to new tools is always followed by the desire to maintain the order.
\end{abstract}

Keywords- interaction, organization, institution, community, society and culture

\section{INTRODUCTION}

The change of paradigm in the national development structure shows the transformation of the economic structure from the dominance of agriculture to the Gross Domestic Product toward industrialization [1], so the government opens the door wide for investment outside the agricultural business. This new investment is an investment in industrial development. The spread of industrial sites to outside Java including South Sulawesi is directed to encourage industrial growth centers in potential areas to be developed as an effort to equalize opportunities and employment, and utilization of local resources optimally while maintaining the sustainability of environmental functions [2].

That description, after the research was held, showed that the development of technology in various industries in the Industrial Area of Makassar had not played a role in the absorption of manpower. The data obtained from the previous author's preliminary study indicate that $64 \%$ of industrial estate population works in agriculture, $2.30 \%$ in industrial sector, $12.70 \%$ in trade, $5.70 \%$ in service sector, $7.30 \%$ in the transport sector, $7.50 \%$ in construction laborers, $0.20 \%$ in finance, and 0.30 electricity and gas and for local communities (indigenous to Makassar Industrial Area). Based on the report of environmental evaluation study conducted by, it is shown that only $1.2 \%$ of workers work in industry sector.

[3] notes two essential conditions for the transition to economic growth, namely (1) the well-spreading creativity of problem-solving skills and (2) attitudes toward manual technical work channeled to innovation in production technology. Hagen searches the presence of creative individuals characterized by the rejection of tradition and accepting new roles. According to Hagen and Mc Cleland's opinion of economic growth is the development of entrepreneurship spirit with the point of discussion on the values of belief and ideology [4]-[7].

The presence of development in an area characterized by industrial growth, commercial production, commercial markets and the emergence of new institutions, often creates obstacles in local communities. This proves the mistake of cultural imperialism that overly believes in the hypodermic model assumption without seeing that empirical reality is not fully dichotomized and linear. Therefore, both [8] emphasize the existence of a mixture of elements of modernity and localism in the form of a local cultural response to modernity. [9], from the beginning has tried to analyze the relationship between economic growth and social structure. Smelser proves the implications of technological development and urbanization in the region of economic activities, family activities, value systems, and stratification structures. In point of fact, development in a region is often hampered by the structure of local communities if not supported by socio-cultural conditions. 
Interaction between ethnic groups in Indonesia has long been valid. Such interaction usually results in acculturation or assimilation and is more of diffusion of dominant groups [10]. This suggests that such interactions occur within a particular social system. The existence of integration within a particular social system, especially in heterogeneous societies is seen by [11] as an ethnic poly social system. Analysis of the interaction and regulation of relationships between ethnics should be seen from the way of thinking in different human contexts. On the other hand, there is also a positive bond that links ethnic groups based on complementary cultural traits and ultimately leads to interdependence or symbiotic situations. Assessment of pluralistic societies received wide attention from experts, with research results such as those by [12],[13].

The problem is how these different lifestyles fill each other, especially the ability of local communities to adapt the processes of change that take place around them so they can play a role and status with the migrant community. Based on this, for the problem that has been formulated to be specific, it needs to be expressed in the form of research hypothesis and also a limitation of the problem so that the scope of research is clearly its limits.

1. The level of understanding of norms by local communities is expected to affect social interaction between communities which is shown through the dynamics of social relations.

2. The loose of networks is expected to affect social interaction between communities which is shown through the dynamics of social relations.

3. The creative of the individual is thought to influence social interaction between communities which is shown through the dynamics of social relations

Social interaction between communities that is shown through the dynamics of social relations is expected to influence changes in the structure of local communities.

\section{RESEARCH METHODS}

This research used analytical descriptive survey method and the type of research is explanation, supported by qualitativequantitative approach that aims to test the research hypothesis with correlation design and influence test. As for the design model of this research is described in structural relationships between variable as follows:

Exp:

$\mathrm{X}_{1}$ : Level of understanding of social norms

$\mathrm{X}_{2}$ : Type of a Social Network

$\mathrm{X}_{3}$ : Kind of Creative Individuals

$\mathrm{Z}$ : Social interaction between communities

$\mathrm{Y}$ : Changes in the structure of local communities

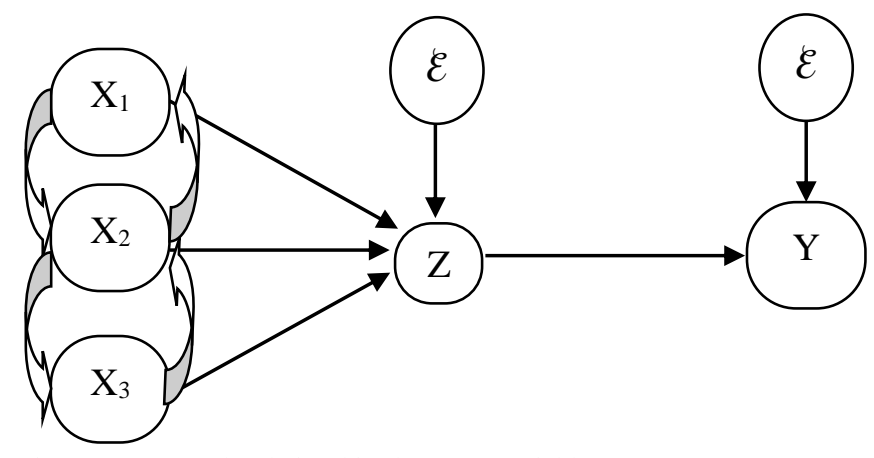

Figure 1 Structural Relationships between Variables

The analysis unit of the supervisory level is the leader of the sub-district, the village apparatus, and the head of the RW, the head of the RT, the public figures as key information including other community figures that are entirely located and domiciled in the research location. Observation is limited then the sampling is based on the technique of proportional random sampling, interviews with questionnaires and free interviews. Data analysis is done in two forms, which are qualitative and quantitative. Qualitatively it is preferred mainly for data obtained through observation involved and interview guidelines. Quantitative analysis through statistical tests of data deserve to be quantified, especially data obtained from the questionnaire.

\section{RESULTS AND DISCUSSION}

A. The level of understanding of norms by local communities in anticipating development is expected to affect social interaction between communities which is shown through the dynamics of social relations.

The research hypothesis, which reads "the level of understanding of the implementation of norms by the local community in anticipating development tends to influence the creation of social interaction between communities which is shown through the dynamics of social relations" is tested based on the paradigm presented in the methodology section in this research report.

By using the transformation data and the formulas used, the calculation results obtained $\mathrm{P}_{\mathrm{ZX} 1}=0.0663 ; \mathrm{t}$ count $=1.770$ and $\mathrm{t}_{\text {table }}=0.9861$. There for $\mathrm{t}_{\text {count }}>\mathrm{t}_{\text {table, then }} \mathrm{H}_{0}$ in reject or $\mathrm{H}_{1}$ accepted or often called significant. This means that from the structural parameters between the levels of understanding of the implementation of norms in anticipating development has a direct positive effect on the interaction of social interaction between communities indicated by the dynamic relationship between communities of $=0.0044$ or $0.44 \%$ concluded the social interaction indicated by the dynamic relationship between communities is determined by the level of understanding of the implementation of the norm, while the rest is determined by other variables beyond the level of understanding of the implementation of norms in anticipating the development. Furthermore, the influence of the level of understanding of the implementation of norms in anticipating the development of social interaction is shown by the dynamic 
relationship between communities through the nature of the social field network $\left(\mathrm{X}_{2}\right)$ of $0.29 \%$, and the influence of the level of understanding of norms in anticipating the development of social interaction indicated by the relationship which dynamic between communities through individual creative $\left(\mathrm{X}_{3}\right)$ by $0.77 \%$. Thus, the amount of influence of the level of understanding of the implementation of norms in anticipating the development of social interactions between communities is shown through the dynamic relationship between communities, either directly or indirectly $1,5 \%$.

As it is stated that the local community is in fact experiencing a condition which shows that on the one hand the people enter into the modern system, on the other hand still based on feudalism and traditional culture. This similar situation gives a picture of a life that is transitional is a society that is going to modern society, that is post agrarian to pre industry. Furthermore [14] calls it a prismatic society. The consequences of a prismatic society should be able to accommodate local culture in the midst of modern life. In fact, according to [15] in his book "Machine Age Maya" that traditional life can continue and even flourish at a higher level in the process of industrialization. This means the creation of a kind of accommodation between industrial development and the surrounding community, so that the developed industry with its production activities and the community can continue to live with the old institutions. Therefore, there should be no inherent conflict between aspects of tradition and modern aspects, so there is no claim "the more modern a society the more it needs the society to give up its tradition".

Overall, the local community cultural system that serves as one of the important and well-known elements of the norm [16] has an effect on social interaction shown through the dynamics of inter-community relationships.

\section{B. The loose of the network in the local community social} field is expected to affect social interaction between communities which is shown through the dynamics of social relations

The research hypothesis which reads "The loose of network in the social field of local community tends to influence the creation of social interaction between communities which is shown through the dynamics of social relations" is tested based on the paradigm presented in the methodology section in this research report.

By using the transformed data and the formulas used then obtained the calculation results $\mathrm{P}_{\mathrm{ZX} 2}=0.1485 ; \mathrm{t}$ count $=$ 2.0667 and $t_{\text {table }}=1.6507$. There for $t_{\text {count }}>t_{\text {table }}$, then $H_{0}$ is rejected or significant. This means that the structural parameters between social field networks have a direct and positive influence on inter-social interaction between communities indicated by the dynamic relationship between communities amounted to $=0.0220$ or concluded $2.20 \%$ of social interaction indicated by the dynamic relationship between communities is determined by the network terrain social, while the rest is determined by other outside variables of the social field network. Furthermore, the influence of social field network to social interaction is shown by the dynamic relationship between the community through norm $\left(\mathrm{X}_{1}\right)$ of $0.29 \%$, and the influence of the social field network to social interaction shown by the dynamic relationship between communities through creative individual $\left(\mathrm{X}_{3}\right) 3.70 \%$. Thus, the amount of influence of social field network to social interaction between communities is shown through dynamic relationship between communities, either directly or indirectly by $6.19 \%$.

The inclusion of community members into the social field of the market network is able to connect them to a life called "high level segmentation" or pluralization life. That is, according to [17] there is a dichotomy between private life and the general field. The cognition of this dichotomy, is relating to individuals in various roles. The facts show that Berger's dichotomy, or Parsons's separation of orientation, has not yet come into being. In fact, according to [18], this pluralization creates a sense of disorientation and confusion called "homeless mind". That is, there are already members of local communities who glorify economic life in other spheres of life. As a result of these circumstances, some respondents experience lifestyle changes, [19] segmentation of lifestyle changes in terms of his own rather than his being. This lifestyle change, specifically [20] refers to "consumer culture". Consumer culture has always highlighted various elements, among others, (1) the emergence of materialistic traits that focus their lives on the consumption of goods, (2) consumer culture gives the place a 'lifestyle' as a special.

Life in the social field of the network gives meaning to the local community. The perception of the "new world" is based on the character and personality traits of the community, which begin to be patterned according to the generation level. There for the level of ability to deal with and take advantage of industry opportunities to be diverse. Generally due to cultural unpreparedness, causing some communities to be excluded and removed. The same situation can be found from various cases expressed by [21]. For a handful of citizens who can enjoy the 'hands' of intermediaries, some still survive and some are withdrawing. For those who survive in general among the younger generation who begin to adapt to the environment. Unlike the case that resigned. They say it is better to die of hunger than to work under the orders and orders of others.

\section{The creative kind of the individual is thought to influence social interaction between communities which is shown through the dynamics of social relations}

The research hypothesis which reads "the existence of creative individual nature in local community tends to influence the creation of social interaction between communities which is shown through the dynamics of social relation" is tested based on the paradigm presented in the methodology section in this research report.

Using the transformed data and the formulas used, the calculation result $\mathrm{P}_{\mathrm{ZX} 3}=0.3731 ; \mathrm{t}$ count $=5.1617$ and $\mathrm{t}_{\text {table }}=$ 1.6507. There for $\mathrm{t}$ count $>\mathrm{t}$ table, then $\mathrm{H}_{0}$ is rejected or significant. This means that from the structural parameters between creative individuals have a positive direct effect on the interaction of social interaction between communities indicated by the dynamic relationship between communities 
amounted to $=0.1392$ or $13.92 \%$ concluded that social interaction is shown by the dynamic relationship between communities determined by the nature creative individuals, while the rest is determined by other variables outside of the nature of the creative individual. Furthermore, the influence of individual nature of creative on social interaction is shown by dynamic relationship between community through norm $\left(\mathrm{X}_{1}\right)$ equal to $0.77 \%$, and influence of individual creative character toward social interaction shown by dynamic relationship between communities through social field network $\left(\mathrm{X}_{2}\right)$ amounted to $3.70 \%$. Thus, the amount of influence of social field network to social interaction between communities is shown through the dynamic relationship between communities, either directly or indirectly by $18.39 \%$. The influence of other variables on $\mathrm{Z}$ out of variable $X_{1}, X_{2}$, and $X_{3}$ equal to $=73.92 \%$.

There for, economic growth and technology gradually and through a long process. Innovation requires not only economic technology, but also with social technology. And that process is pleased with the creative individual who creates a special kind of social relationship. From the above approaches and concepts, the indications of social technology or creative individuals are: (1) rejection of tradition, (2) ready to accept new ideas and experiences, (3) participation in high mass media, (4) to have high work motivation. This tracking of social technologies is the same as any other variable, i.e. through measurement of any indicator that has been formulated through or based on responses to some statements.

Attitudes and behavior reject tradition, more to Kohl's (1968) statement that "it is possible that many people become modern at little value, but traditional to others". Therefore, the understanding of tradition (in the sense of rejection) does not cover all aspects of life. Rejecting tradition, only limited to values that can limit the movement of individuals. Values that are considered to limit the movement of individuals include: 1) glorify simple life; 2) character of humble self; 3) preservation of paternalistic values.

\section{Social interaction between communities that is shown through the dynamics of social relations is expected to influence changes in the structure of local communities}

The research hypothesis which reads "social interaction between communities which is shown through the dynamics of social relations tend to influence changes in local community structure" is tested based on the paradigm presented in the methodology section in this research report.

Using the transformed data and the formulas used, $\mathrm{P}_{\mathrm{YZ}}=$ $0.1027 ; \mathrm{t}_{\text {count }}=1.6780$ and $\mathrm{t}_{\text {table }}=1.6506$. There for $\mathrm{t}_{\text {count }}>$ $t_{\text {table, }}$, then $\mathrm{H}_{0}$ is rejected or significant. This means that from the structural parameters between social interactions indicated by the dynamic relationship between communities has a positive direct effect on the change of community structure of $=0.010553$ or $1.06 \%$ concluded structural changes determined by social interaction indicated by the dynamic relationship between communities, while the remainder is determined by other variables outside of the social interactions indicated by the dynamic relationship between the communities. The influence of other variables on $\mathrm{Y}$ out of variable $\mathrm{Z}$ equal to $=98.94 \%$. The various shifts and changes that arise in the local community are part of the interaction of social interactions that are shown through the dynamics of social relations. Changes in the role are that followed the shifting pattern of relationships, providing an atmosphere toward a new orientation in various areas of life. This whole change takes place between different cultures, especially among local cultures. All of these changes will ultimately lead to an integrated life as a whole. For the local community (as a result of this study's findings) begins with mental and behavioral adjustment to an objective social situation (outside of itself). Efforts to adapt to a wider system are at the core of integration issues. Integration requires an attitude and views and patterns of harmonious relationships from and among the perpetrators so that the creation of homogeneity on patterns of values and norms between groups and structural that exists.

Recognized by [22] is that the process to create harmony and homogeneity is not a process that runs fast and smooth because it is a mental process associated with attitudes and views based on their respective cultures. Correspondingly, as [23] argues; [24] sees integration as the interaction of various cultural patterns will revolve around the cultural values, norms and customs of various systems.

Regarding the influence between research variables as described in the complete discussion chapter we can see in the following figure 2 .

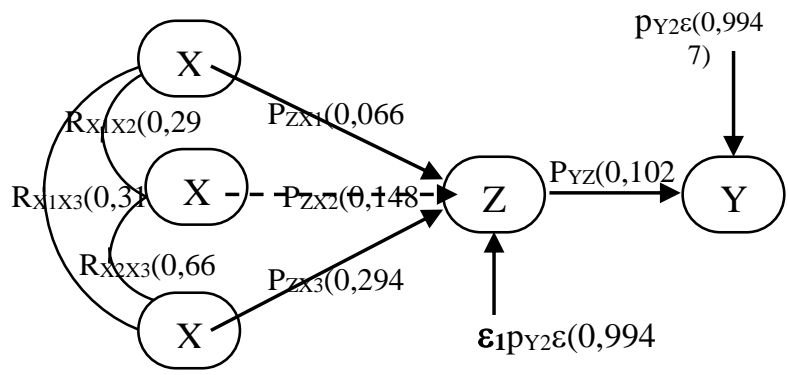

Fig.2 The Influence of Variable Variables Completely

\section{CONCLUSION}

Taking into account the results of discussion and testing the hypothesis, it can be concluded as follows:

1. Shifting understanding of the implementation of the norms has a significant effect on the attitude of compromise, tolerance and cooperation process. And can instead serve as a "mechanism" against conflict. The shift is limited to values and norms whose existence can limit the movement of the individual.

2. Shifts in values and norms give the opportunity for "loose structure" among local communities. The pattern of territorial networks marked by a "close knit" relationship pattern tends to shift towards "loose knit" especially to other communities. The looser structure can be seen from indicators of visiting patterns, borrowing patterns, exchange patterns and inviting patterns of eating. Most of the respondents, especially from the 
younger generation, disagreed on relationships that were limited to their own environment.

3. Innovation in life is determined by economic technology and social technology. This process is related to the existence of creative individuals. The emergence of creative individuals is part of the support of values and norms and the expansion of social networks. In particular this is evidenced by the attitude towards the dynamic relationship pattern that is getting looser.

4. Significantly influence positive in creating dynamic relationships through social interactions between communities that are configured in the attitude of tolerance, compromise and cooperation. Based on these responses, proving that the social interaction process between communities that is shown through the dynamics of social relations has a significant and positive effect on the change of local community structures, especially in the scope of structural simplification of local communities by $1.06 \%$ (see the results of hypothesis 4 ).

\section{ACKNOWLEDGMENT}

Thanks to the Dean of the Faculty of Social Sciences who have provided financial support for this research.

\section{REFERENCES}

[1] G. Gereffi and D. L. Wyman, Manufacturing miracles: paths of industrialization in Latin America and East Asia, vol. 1189. Princeton University Press, 2014.

[2] H. S. Tooranloo, M. H. Azadi, and A. Sayyahpoor, "Analyzing factors affecting implementation success of sustainable human resource management (SHRM) using a hybrid approach of FAHP and type-2 fuzzy DEMATEL," J. Clean. Prod., vol. 162, pp. 1252-1265, 2017.

[3] E. E. Hagen, "On the theory of social change: How economic growth begins," 1962.

[4] Z. A. Rengifurwarin, A. H. Akib, U. N. M. Jasruddin, and R. Salam, "Snapshot of Public Service Quality in The Center For Integrated Business Service (CIBS), Cooperative Micro Small and Medium Enterprises (CMSME), Maluku Province, Indonesia," J. Entrep. Educ., vol. 21, no. 3, 2018.

[5] J. Papilaya, T. R. Soisa, and H. Akib, "The Influence of Implementing the Strategic Policy in Creating Business Climate, Business Environment and Providing Support Facilities towards Business Empowerment on Small Medium Craft enterprises in Ambon Indonesia," Int. Rev. Manag. Mark., vol. 5, no. 2, pp. 8593, 2015.

[6] A. Syam, H. Akib, M. Yunus, and S. Hasbiah, "Determinants of entrepreneurship motivation for students at educational institution and education personnel in Indonesia.," J. Entrep. Educ., vol. 21, no. $2,2018$.

[7] M. Jufri, H. Akib, S. Ridjal, R. Sahabuddin, and F. Said, "Improving Attitudes And Entrepreneurial Behaviour Of Students Based On Family Environment Factors At Vocational High School In Makassar," J. Entrep. Educ., vol. 21, no. 2, pp. 1$14,2018$.

[8] J. Friedman, "Being in the world: globalization and localization," Theory, Cult. Soc., vol. 7, no. 2-3, pp. 311-328, 1990.

[9] N. Smelser, Toward a theory of modernization. 1964.

[10] Y. K. Garna, Orang Baduy. Penerbit Universiti Kebangsaan Malaysia, 1987.

[11] F. W. Diehl, "Revenue farming and colonial finances in the
Netherlands East Indies, 1816-1925," in The Rise and Fall of Revenue Farming, Springer, 1993, pp. 196-232.

[12] F. Barth, "éd.(1969): Ethnic Groups and Boundaries," Soc. Organ. Cult. Differ. Bergen.

[13] G. Fennell, C. Phillipson, and H. Evers, The sociology of old age. Open University, 1988.

[14] F. W. Riggs, Administration in developing countries: The theory of prismatic society. Houghton Mifflin, 1964.

[15] J. K. Adelman-McCarthy et al., "The fourth data release of the Sloan Digital Sky Survey," Astrophys. J. Suppl. Ser., vol. 162, no. 1, p. 38, 2006.

[16] W. Firey, C. P. Loomis, and J. A. Beegle, "The fusion of urban and rural," Cities Soc., pp. 214-222, 1957.

[17] P. L. Berger and T. Luckmann, A construção social da realidade: tratado de sociologia do conhecimento. Vozes Petrópolis, 1974.

[18] S. Soemardjan, "Stereotip Etnik, Asimilasi, Integrasi Sosial," Jakarta Yayasan Ilmu-Ilmu Sos., 1988.

[19] S. Poespowardojo, Kebudayaan Indonesia dilihat dari sudut perkembanganny. Fakultas Sastra, Universitas Indonesia, 1987.

[20] M. Featherstone, "Leisure, symbolic power and the life course," Sociol. Rev., vol. 33, no. S1, pp. 113-138, 1985.

[21] T. N. Effendi, Sumber daya manusia, peluang kerja, dan kemiskinan. Tiara Wacana Yogya, 1993.

[22] M. F. Nimkoff, "Is the joint family an obstacle to industrialization?," Int. J. Comp. Sociol., vol. 1, p. 109, 1960.

[23] J. I. Sorokin, "Vertical distribution of phytoplankton and the primary organic production in the sea," ICES J. Mar. Sci., vol. 26, no. 1 , pp. $49-56,1960$.

[24] T. Parsons and G. M. Platt, The american university. Harvard University Press, 1973. 